\title{
Study on Geological Disaster Susceptibility in Nanyang and Xiangyang Basin
}

\author{
Yongpeng $\mathrm{Fu}^{1}$, Yiyong $\mathrm{Li}^{1}$, Bei Wang ${ }^{2}$, Lei Wang ${ }^{1}$, Xueping $\mathrm{Li}^{2}$ \\ ${ }^{1}$ Geological Survey Center in Wuhan, China Geological Survey, Wuhan, China \\ ${ }^{2}$ Faculty of Engineering, China University of Geosciences, Wuhan, China
}

\section{Email address:}

418389691@qq.com(Yongpeng Fu),854052762qq.com (YiyongLi), 1251072542@qq.com(Bei Wang),40569385@qq.com(Lei Wang), 1422332187@qq.com (XuepingLi)

\section{To cite this article:}

Yongpeng Fu, Yiyong Li, Bei Wang, Lei Wang, Xueping Li. Study on Geological Disaster Susceptibility in Nanyang and Xiangyang Basin. International Journal of Environmental Protection and Policy. Vol. 6, No. 2, 2018, pp. 56-62. doi: 10.11648/j.ijepp.20180602.16

Received: April 20, 2018; Accepted: May 16, 2018; Published: June 21, 2018

\begin{abstract}
Nanyang and Xiangyang Basin is located in the east of Qinling Mountains and Daba Mountain, and the west of Dabie Mountain and Tongbai Mountain. Its north is the Funiu Mountain seated at the east end of Qinling Mountain, and the south is the east end of the Daba Mountains. The main geological environment problems in the area include collapse, landslides, ground fissure, high fluorine water, expansive soil etc. On the basis of collecting the data of geological environment in the basin area, the article regards Nanyang and Xiangyang Basin area and its surrounding area as research objects, and then builds the geological environment database of the study area through GIS platform. Based on the analysis of the factors that affect the geological disasters susceptibility in the study area, an evaluation index system of geological disaster susceptibility was established. The paper expounds the process and steps of applying analytic hierarchy process (AHP) to geological disaster susceptibility assessment, and uses this method (AHP) to establish the hierarchical analysis structural model and the judgment matrix of geological disaster susceptibility comprehensive evaluation, so as to determine the influence of geological disasters. The weight of degree factors establishes a mathematical model for the evaluation of susceptibility to catastrophic disasters in geological disasters and comprehensive evaluation of susceptibility to geology in regional geological disasters. Through using the evaluation module developed by MapGIS, the geological disaster susceptibility of the study area can be divided, and there are four zones: highly-prone area, mid-prone areas, low-prone areas, undeveloped area. This article analyzes the causes of geological disaster susceptibility in the study area, and the research results can provide the basis for geological environment management, planning and disaster prevention and reduction in the study area. At the same time, the reliability of the evaluation results is discussed by comparing the evaluation results with actual geological disasters.
\end{abstract}

Keywords: Geological Disaster Susceptibility, GIS, Evaluation, AHP

\section{Introduction}

With the development of Geographic Information System (GIS) technology, the application of GIS technology in geological disasters has attracted the attention of many researchers [1-8]. Based on the GIS platform, different evaluation methods and mathematical models have been used to study the geological disaster zone division and the results are abundant.

This paper takes the geological disasters in the Nanyang and Xiangyang Basin as the research object. Based on the analysis of the development degree and influencing factors of the geological disasters in the study area, a geological disaster evaluation index system is established. Then, with the support of the MAPGIS software, the AHP method is used to analyze the geological disaster susceptibility in Nanyang and Xiangyang Basin [9-12]. The zoning map of the geological disaster susceptibility in the Nanyang and Xiangyang Basin was mapped out to provide geological basis for land planning and land use. At the same time, the reliability of the evaluation results is discussed by comparing the evaluation results with actual geological disasters. 


\section{Overview of the Study Area}

\subsection{Study Area}

Nanyang and Xiangyang Basin is located in the east of Qinling Mountain-Daba Mountain, west of Dabie Mountain-Tongbai Mountain, north of which is the Funiu Mountain, south of which is the Daba Mountain. The surrounding mountains form a basin, the basin have a total area of approximately $46000 \mathrm{~km}^{2}$, a population of 16.582 million people and a population density of approximately 358.3 persons $/ \mathrm{km}^{2}$. The northern part of the basin belongs to Nanyang, Henan, and the south belongs to Xiangyang, Hubei. The middle part of the basin is an alluvial plain with an elevation of $80-120 \mathrm{~m}$. There are undulating hills on the edge of the basin, with the elevation of $140-200 \mathrm{~m}$. It is in the transitional zone from subtropical to warm temperate zone. It is a typical semi-humid continental monsoon climate, with an annual rainfall of 800 to $1000 \mathrm{~mm}$.

\subsection{Regional Geological Background}

\subsubsection{Geological Structure}

The basin is located near the boundary of the first-order structure of the North China plate and the Yangtze plate, and is a faulted basin formed since the Yanshan movement. In addition to the continuous activities of the Qingfeng-Guangji fault since the Quaternary in the basin, the entire region is basically in a stable state. The main direction of the fault is northeast to southwest. The Luonan-Luanchuan fault zone, the Waxuezi-Xiaoluogou fault, the Zhuyangguan-Xiaguan fault zone, the Danfeng-Zhenping fault zone, the Chengkou-Fangxian fault, and the Songyu-Guishan fault cross study area.

\subsubsection{Formation Lithology}

The Mesozoic strata along the regional fault zone in the study area were distributed in the northeast-southwest direction. Most of them were continental fault basins, mainly including the Triassic, Jurassic, and Cretaceous strata. The Lower Triassic is mainly neritic facies limestone and argillaceous limestone, and the middle and upper systems are fluvial sandstone, siltstone, and mudstone. The Jurassic is mainly exposed to the upper system and distributed in the eastern part of Nanzhao County, the main lithology is fluvial sandstone, siltstone, and mudstone. The lithology of the Cretaceous is mainly sandy clay rock, marlstone sandstone and glutenite. The Cenozoic in the study area includes the Paleogene, the Neogene, and the Quaternary. The main lithology of the Paleogene stratum is glutenite, sandstone and mudstone. The sedimentary process of the Neogene is very complete, the lithology is conglomerate, glutenite, coarse-grained sandstone, argillaceous medium-grained sandstone, sandy mudstone, shaly fine sandstone, and sandy mudstone, Holocene Series is located on both sides of major rivers and tributaries, the lithology is gravel layer, silt layer, Most of them are floodplain deposits, and some of them are lakes, swamps, and floodplain sediments.

\subsubsection{Hydrogeological Conditions}

According to the groundwater storage medium and the hydrogeological conditions, groundwater can be divided into four types: bedrock fissure water, carbonate karst fissure water, loose rock pore water and clastic rock pore water.

The bedrock fissure water generally receives atmospheric precipitation, and its runoff pathway is short. It supplies the river water with spring water or subsurface flow, and has the dynamic changes with seasons. Carbonate karst fissure water mainly uses atmospheric precipitation as recharge source and subsurface flow and spring water as the main excretion methods. Affected by karst development, distribution and other factors, the runoff conditions are relatively complex. Loose rock pore water is divided into shallow water and deep water. Shallow water uses atmospheric precipitation and surface water as the main source of recharge. It is mainly consumed by evaporation and mining, and has the dynamic changes with meteorological and hydrological factors. The deep water receives atmospheric precipitation and shallow water supply, recharging the adjacent shallow water layer.

\subsubsection{Features of Geological Disaster Development}

In the study area, collapses, landslides, and debris flow disasters are mainly distributed in the hills and mountains around the basin, including Xixia, Xichuan, Nanzhao and Neixiang counties. The distribution of mountainous geological disasters is controlled by topographic conditions with obvious regional zoning characteristics, such as the coastal areas along the Han River, densely populated areas and more economically developed townships.

\section{Evaluation Index Establishment}

\subsection{Establishment of Evaluation Index System}

Based on the analysis of the existing geological disasters in the Nanyang and Xiangyang Basin, the paper selected geological conditions (A), hydrogeological conditions (B), and geological disasters $(\mathrm{C})$ as first-class evaluation indicators. Based on existing research results and experience in geological disaster prevention, The geological disaster assessment indicators in the study area are graded according to Figure 1. 


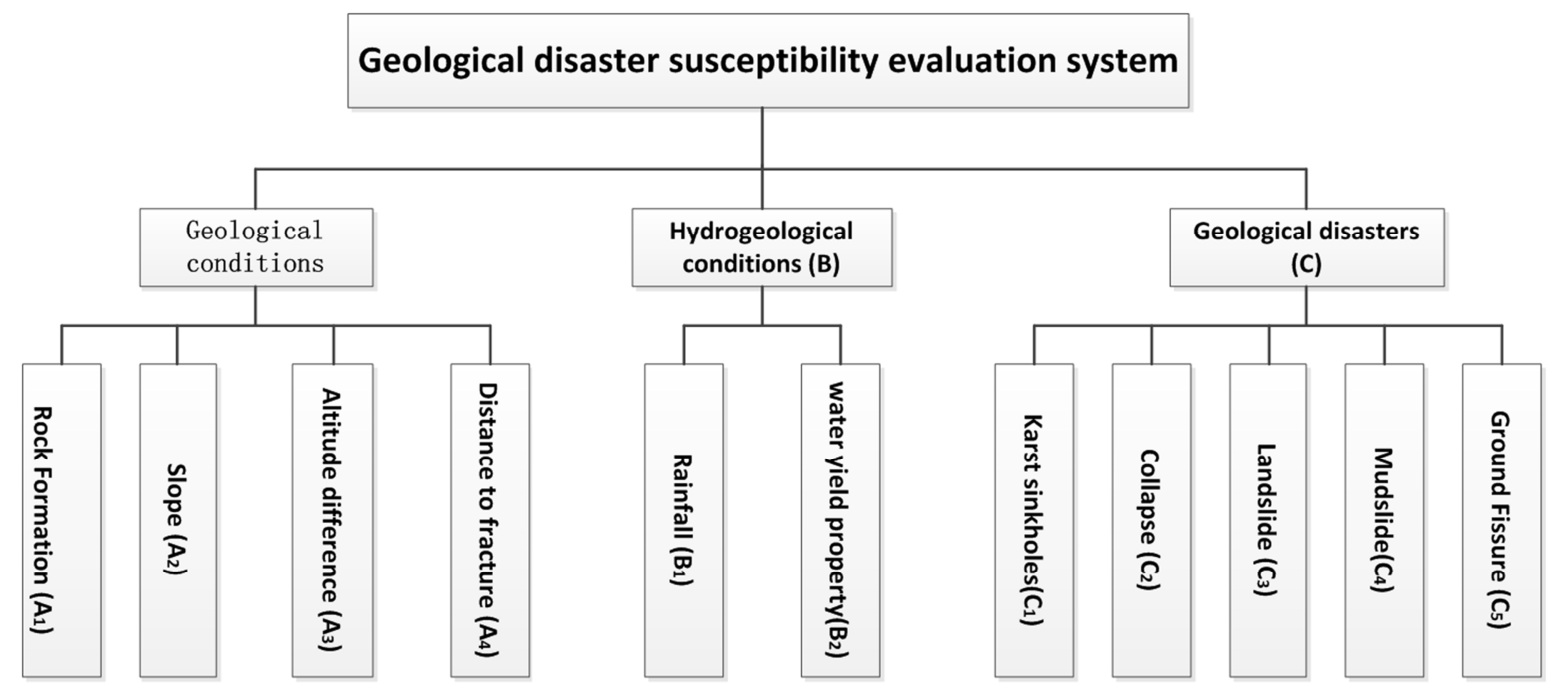

Figure 1. Evaluation Index System.

\subsection{Evaluation Index Classification}

(1) Geological conditions (A)

1) Rock Formation $\left(A_{1}\right)$

The rock formation in the study area is classified into six levels:

A flaked metamorphic rocks; B granular igneous rocks; C sedimentary clastic rocks; D carbonates; E semi-diagenetic rocks; $F$ loose soils.

2) Slope $\left(\mathrm{A}_{2}\right)$

The slope of the study area is divided into four levels: $0-10^{\circ}$, $10-20^{\circ}, 20-30^{\circ}, \geq 30^{\circ}$. The higher the slope, the higher the susceptibility to geological disasters.

3) Altitude difference $\left(\mathrm{A}_{3}\right)$

The altitude difference is divided into 7 levels: 0 - 20m, 20 50m, $50-100 \mathrm{~m}, 100-150 \mathrm{~m}, 150-200 \mathrm{~m}, 200-300 \mathrm{~m}$, and $\geq 300 \mathrm{~m}$. The greater the altitude difference, the higher the susceptibility to geological disasters.

4) Distance to fracture $\left(A_{4}\right)$

According to the distance from the fracture, the distance factor between the study area and the fracture is divided into four levels: $0-0.5 \mathrm{~km}, 0.5-2 \mathrm{~km}, 2-5 \mathrm{~km}$, and $\geq 5 \mathrm{~km}$. The smaller the distance from the fracture, the higher the susceptibility to geological disasters.

(2) Hydrogeological conditions (B)

1) Rainfall $\left(B_{1}\right)$

The rainfall in the study area is divided into four grades: $700-800 \mathrm{~mm}, 800-900 \mathrm{~mm}, 900-1000 \mathrm{~mm}$, and $1000-1100 \mathrm{~mm}$. The greater the rainfall, the higher the susceptibility to geological disasters.

2) Water yield property $\left(B_{2}\right)$

According to the hydrogeological conditions in the study area, the water yield property is divided into five categories. Class1 has the least impact on geological disasters.

(3) Geological disasters (C)

1) Karst sinkholes $\left(\mathrm{C}_{1}\right)$

The karst sinkholes in the study area is mainly caused by gypsum rock, salt rock halite, and limestone. The evaluation factor is divided into two grades of "yes" or "no".

2) Collapse $\left(\mathrm{C}_{2}\right)$

The evaluation factor in the study area is divided into two grades: "yes" or "no".

3) Landslide $\left(\mathrm{C}_{3}\right)$

The evaluation factor in the study area is divided into two grades: "yes" or "no".

4) Mudslide $\left(\mathrm{C}_{4}\right)$

The evaluation factor in the study area is divided into two grades of "yes" or "no".

5) Ground Fissure $\left(\mathrm{C}_{5}\right)$

The evaluation factor in the study area is divided into two grades of "yes" or "no".

\subsection{Evaluation Factor Weight Calculation}

Based on the existing research results and experience in the geological disasters prevention, the weights of each indicators obtained by using the Analytic Hierarchy Process (AHP) are as follows.

Table 1. First-level evaluation index matrix and weights.

\begin{tabular}{lllll}
\hline & Geological conditions & Hydrogeological conditions & Geological disasters & Weights \\
\hline Geological conditions & 1 & 1.67 & 0.71 & 0.33333 \\
Hydrogeological conditions & $3 / 5$ & 1 & 0.43 & 0.20000 \\
Geological disasters & $7 / 5$ & 2.33 & 1 & 0.46667 \\
\hline
\end{tabular}

$\mathrm{CI}=-0.0083 ; \mathrm{RI}=0.58 ; \mathrm{CR}=-0.00144$

As can be seen from the table, CR is less than 0.1 and the matrix conforms to the consistency check. 
Table 2. Second-level evaluation index - geological condition matrix and weights.

\begin{tabular}{llllll}
\hline Geological conditions & Rock formation & Slope & Altitude difference & Distance to fracture & Weights \\
\hline Rock formation & 1 & 0.2 & 0.4 & 0.17 & 0.06897 \\
Slope & $5 / 1$ & 1 & 2 & 0.83 & 0.34483 \\
Altitude difference & $5 / 2$ & 0.5 & 1 & 0.42 & 0.17241 \\
Distance to Fracture & $6 / 1$ & 1.2 & 2.4 & 1 & 0.41379 \\
\hline
\end{tabular}

$\mathrm{CI}=0 ; \mathrm{RI}=0 ; \mathrm{CR}=0$

As can be seen from the table, CR is less than 0.1 and the matrix conforms to the consistency check.

Table 3. Second-level evaluation index - hydrogeological conditions matrix and weights.

\begin{tabular}{llll}
\hline Hydrogeological conditions & Rainfall & Water yield property & Weights \\
\hline Rainfall & 1 & 1.5 & 0.60000 \\
Water yield property & $2 / 3$ & 1 & 0.40000 \\
\hline
\end{tabular}

$\mathrm{CI}=0 ; \mathrm{RI}=0 ; \mathrm{CR}=0$

As can be seen from the table, CR is less than 0.1 and the matrix conforms to the consistency check.

Table 4. Secondary Evaluation Index - Geological Disaster Matrix and Weights.

\begin{tabular}{lllllll}
\hline Human engineering activities & Karst sinkholes & Collapse & Landslide & Mudslide & Ground Fissure & Weights \\
\hline Karst sinkholes & 1 & 0.6 & 0.6 & 0.6 & 1 & 0.14285 \\
Collapse & $5 / 3$ & 1 & 1 & 1 & 1.67 & 0.23810 \\
Landslide & $5 / 3$ & 1 & 1 & 1 & 1.67 & 0.23810 \\
Mudslide & $5 / 3$ & 1 & 1 & 1 & 1.67 & 0.23810 \\
Ground Fissure & 1 & 0.6 & 0.6 & 0.6 & 1 & 0.14285 \\
\hline
\end{tabular}

$\mathrm{CI}=0 ; \mathrm{RI}=0 ; \mathrm{CR}=0$

As can be seen from the table, CR is less than 0.1 and the matrix conforms to the consistency check.

Table 5. The final results of the 1st and 2nd indicator weights of geological disasters in the Nanyang and Xiangyang Basin.

\begin{tabular}{|c|c|c|c|c|}
\hline Weights & Geological conditions (A) & Hydrogeological conditions (B) & Geological disasters (C) & Index synthesis Weights Wi \\
\hline Indicator & 0.33333 & 0.20000 & 0.46667 & $(\mathbf{i}=1, \ldots 11)$ \\
\hline Rock formation $\left(A_{1}\right)$ & 0.06897 & & & 0.02299 \\
\hline Slope $\left(A_{2}\right)$ & 0.34483 & & & 0.11495 \\
\hline Altitude difference $\left(\mathrm{A}_{3}\right)$ & 0.17241 & & & 0.05747 \\
\hline Distance to fracture $\left(\mathrm{A}_{4}\right)$ & 0.41379 & & & 0.13794 \\
\hline Rainfall $\left(\mathrm{B}_{1}\right)$ & & 0.60000 & & 0.12000 \\
\hline Water yield property $\left(\mathrm{B}_{2}\right)$ & & 0.40000 & & 0.08000 \\
\hline Karst sinkholes $\left(\mathrm{C}_{1}\right)$ & & & 0.14285 & 0.06666 \\
\hline Collapse $\left(\mathrm{C}_{2}\right)$ & & & 0.23810 & 0.11111 \\
\hline Landslide $\left(\mathrm{C}_{3}\right)$ & & & 0.23810 & 0.11111 \\
\hline Mudslide $\left(\mathrm{C}_{4}\right)$ & & & 0.23810 & 0.11111 \\
\hline Ground Fissure $\left(\mathrm{C}_{5}\right)$ & & & 0.14285 & 0.06666 \\
\hline
\end{tabular}

According to the the impact of geological disasters, the evaluation factors are scored, and the score range is $[0,100]$. A score of 0 indicates that the grade has no effect on geological disasters, and a score of 100 indicates the impact of the grade on geological hazards is maximum. The quantitative criteria for graded indicators are shown in Table 6.

Table 6. Quantification standards for graded indicators.

\begin{tabular}{llll}
\hline First-level indicators & Second-level indicators & Second-level indicators classification and quantification \\
\hline & & loose soils & 100 \\
& & semi-diagenetic rocks & 80 \\
& & flaky metamorphic rocks & 60 \\
Reological conditions $(A)$ & carbonates & 40 \\
& & sedimentary clastic rocks & 20 \\
& & granular igneous rocks & 0 \\
& & divided into 4 levels by range & \\
& & {$[0 \sim 10(0) ; 10 \sim 20(30) ; 20 \sim 30(75) ; \geq 30(100)]$} \\
\hline
\end{tabular}




\begin{tabular}{|c|c|c|}
\hline First-level indicators & Second-level indicators & Second-level indicators classification and quantification \\
\hline \multirow{5}{*}{ Hydrogeological conditions (B) } & Altitude difference $\left(\mathrm{A}_{3}\right) / \mathrm{m}$ & $\begin{array}{l}\text { divided into } 7 \text { levels by range }[\leq 20(0) ; 20 \sim 50(20) ; 50 \sim 100(30) ; 100 \sim 150(50) \text {; } \\
150 \sim 200(60) ; 200 \sim 300(80) ;>300(100)]\end{array}$ \\
\hline & Distance to fracture $\left(\mathrm{A}_{4}\right) / \mathrm{m}$ & divided into 4 levels by range \\
\hline & & divided into 4 levels by range \\
\hline & Rainfall $\left(\mathrm{B}_{1}\right) / \mathrm{mm}$ & {$[700 \sim 800(30) ; 800 \sim 900(50) ; 900 \sim 1000(80) ; 1000 \sim 1100(100)]$} \\
\hline & Water yield property $\left(\mathrm{B}_{2}\right)$ & divided into 5 levels by range [I(0); II(20); III(40); IV(60); V(80)] \\
\hline \multirow{5}{*}{ Geological disasters $(\mathrm{C})$} & Karst sinkholes $\left(\mathrm{C}_{1}\right)$ & [yes (100); no (0)] \\
\hline & Collapse $\left(\mathrm{C}_{2}\right)$ & [yes (100); no (0)] \\
\hline & Landslide $\left(\mathrm{C}_{3}\right)$ & [yes (100); no (0)] \\
\hline & Mudslide $\left(\mathrm{C}_{4}\right)$ & [yes (100); no (0)] \\
\hline & Ground Fissure (C5) & [yes (100); no (0)] \\
\hline
\end{tabular}

\section{Geological Disaster Susceptibility Evaluation}

Based on the basic geological data in the study area, the characteristics of geological disasters in the Nanyang and Xiangyang Basin were analyzed, and the spatial database of geological disasters in the study area was established using GIS technology, including a graphic database and an attribute database. In the process of building a database, the basic maps are managed hierarchically, and the spatial data is decomposed into basic layers of single elements, such as the basic geography layers, contour layers, geomorphology layers, lithology layers, geological structure layers, and so on.

According to the previously established geological disaster assessment index system in the study area, 11 major evaluations index were included: rock group, slope, height difference, distance to fracture, water yield property, rainfall, collapse, landslide, mudslide, karst subsidence, and ground fissures. Based on the evaluation module developed by the MapGIS platform, the grid method is used to calculate the score of the geological disaster susceptibility in the study area, and to evaluate the susceptibility to geological disasters in the study area.

\subsection{Evaluation Unit Meshing}

In the application of GIS, the units are commonly divided as follows: regional unit method, sub-basin method, uniform condition unit method, and grid unit method. This paper intends to adopt grid unit method. According to the actual kilometer grid, a square grid unit method was used to divide the entire study area into discrete grids of uniform size and shape (usually the study area was an irregular quadrangle). The study area includes basin areas and basin perimeter areas (geographic location: $111^{\circ} 20^{\prime} \sim 113^{\circ} 40^{\prime} \mathrm{E}, 31^{\circ} 40^{\prime} \sim 33^{\circ} 30^{\prime} \mathrm{N}$ ). The study area was divided into $1 \mathrm{~km} \times 1 \mathrm{~km}$ grid units, a total of 44942 grids.

\subsection{Evaluation Results and Analysis}

The formula of AHP is used to obtain scores for each evaluation grid unit, and the score range of all evaluation units is $[0,68]$. The score range is divided as follows: undeveloped areas, low-prone areas, mid-prone areas and high-prone areas, with the scope of $[0,44],[44,61],[61,65]$ and $[65,68]$. The statistical results of the geological disasters susceptibility evaluation in the study area are shown in Table 7 . The zoning of the geological disaster susceptibility in the study area is shown in Figure 2.

(1) highly-prone area

The geological disasters are mainly mountainous disasters in the basin margin area, which mainly occur in the areas surrounding Danjiangkou, Xiangyang, Nanzhang, Xixia, Neixiang, Xichuan, Nanzhao, Gucheng and Tongbai County, accounting for $4.41 \%$ of the study area, of which landslides occur at the highest frequency. The zoning of high-prone areas for geological disasters in the study area is mainly distributed in the Quaternary Holocene (Qh), Upper Pleistocene (Qp2), Middle Pleistocene (Qp3), Neogene loose rock areas and the areas with high differences and steep slopes. Rainfall is one of the main factors that leads to geological disasters in the study area. There are many large faults in the western part of the study area, and relatively complex geological background conditions are formed, causing frequent geological disasters.

(2) mid-prone areas

The geological disasters in mid-prone areas are mainly distributed in the bordering area between Nanzhao County and Xixia County. In terms of geomorphological types, it is mainly located in the mountains where slopes and altitude difference are relatively large. The hydrogeological conditions are mainly grade III of water yield property, and the geological disasters are located on the geological structure near the major fault zone.

(3) low-prone areas

The low-prone areas of geological disasters are mainly located in Zaoyang, Suizhou, Wugang and Nanzhao Counties. These areas are generally hilly areas with relatively small slopes and altitude differences, and are located far from the fault zone.

(4) undeveloped area

The undeveloped areas of geological disasters are mainly located at a distance from the fault zone, and they are plains and areas with low rainfall and low levels of water yield property.

In summary, the geological disasters in the study area was mainly controlled by rock formation, slopes, altitude differences, faults, rainfall, water yield property, and karst collapse, collapse, landslide, debris flow, and ground fissures. 
Table 7. Statistics of evaluation results in the study area.

\begin{tabular}{lllllll}
\hline Number & Starting value & End point value & Susceptibility level & Number of grid units & Area $\left.\mathbf{( k m}^{2}\right)$ & Proportion \\
\hline 1 & 0 & 44 & undeveloped area & 29266 & 29266 & $65.12 \%$ \\
2 & 44 & 61 & Low-prone areas & 11555 & 11555 & $25.71 \%$ \\
3 & 61 & 65 & mid-prone areas & 2139 & 2139 & $4.76 \%$ \\
4 & 65 & 68 & highly-prone area & 1982 & 1982 & $4.41 \%$ \\
Total & 0 & 68 & & 44942 & 44942 & $100 \%$ \\
\hline
\end{tabular}

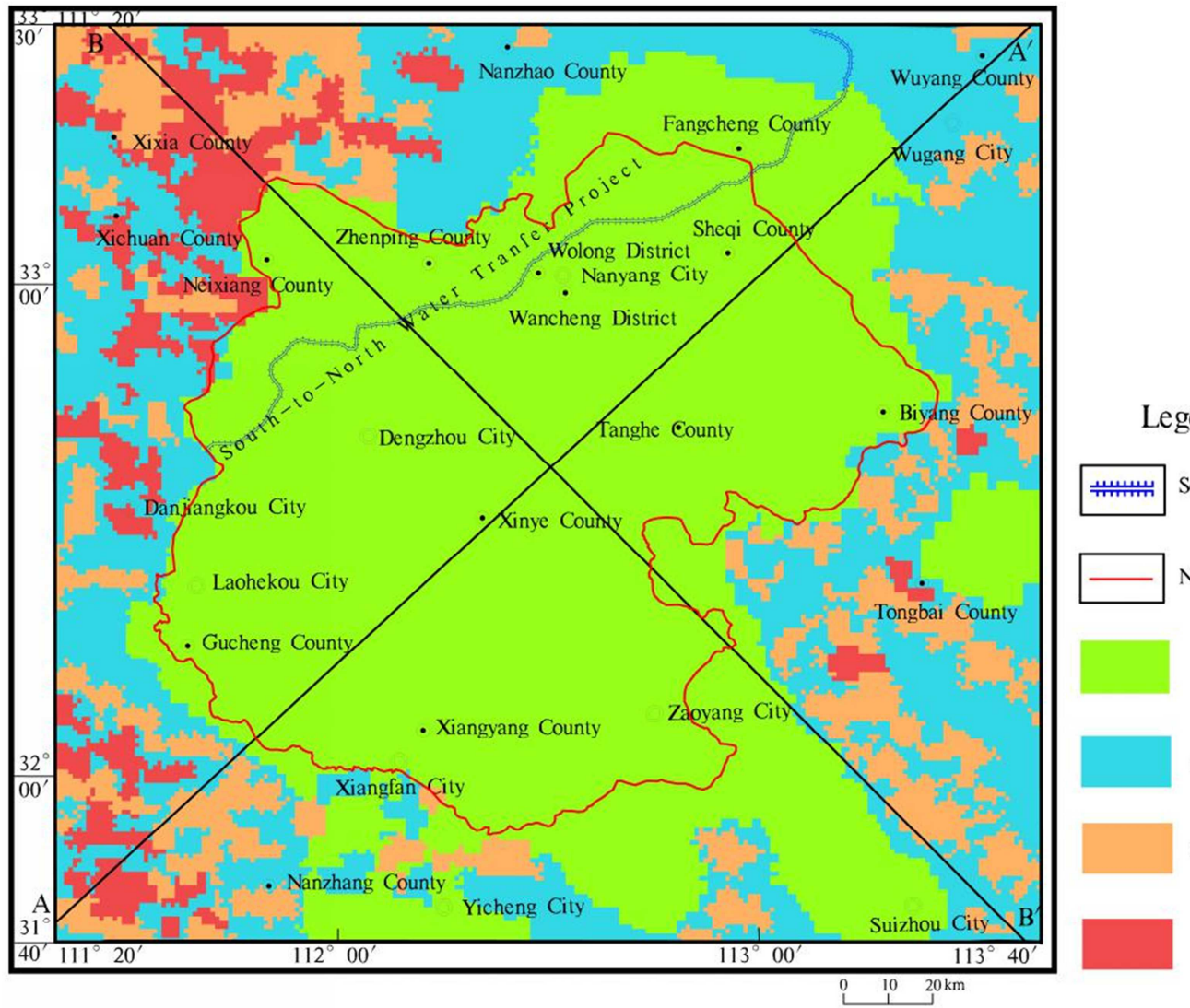

Legend

South-to-North Water Transfer Project

Nanyang and Xiangyang Basin Range

Undeveloped area

Low-prone areas

Mid-prone areas

Highly-prone area

Figure 2. Zoning map of geological disaster Susceptibility in the study area.

\section{Conclusion}

This paper establishes a suitable index system for geological disaster susceptibility evaluation, and conducts a geological disaster susceptibility evaluation division in the Nanyang and Xiangyang Basin area. Rock formation, slope, height difference and so on are selected as evaluation indicators. Based on GIS technology, AHP are used to divide the geological disaster susceptibility areas in the study area. Basically, it conforms to the law of intensity of action in disaster-prone areas. The results are in good agreement with the actual disaster situation summary. They have been well verified in recent geological disaster investigations and reflect the geological disasters in the region.

The study of the macro-developmental degree of geological disasters is the basis for risk assessment, further detailed investigations, and regional geological disasters early warning and forecasting. With the gradual accumulation of data, it will provide an in-depth understanding of the causes of disasters in various regions, improve the evaluation accuracy and prediction accuracy, and better serve disaster reduction and disaster prevention.

The high-prone areas of geological disasters in the study area are mainly distributed in Danjiangkou City, Xiangyang City, Nanzhang County, Xixia County, Neixiang County, Xichuan County, Nanzhao County, Gucheng County, Tongbai County and other surrounding areas, with an area of approximately $1982 \mathrm{~km}^{2}$ and approximately $4.41 \%$ of the study area, of which landslide-like geological disasters occurred at the highest frequency. The mid-prone areas of geological disasters are mainly distributed in the bordering area between Nanzhao County and Xixia County, and around Nanzhao County and Tongbai County, with an area of approximately $2139 \mathrm{~km}^{2}$ and approximately $4.76 \%$ of the study area. The low-prone areas of geological disasters are mainly located in Zaoyang, Suizhou, Wugang and Nanzhao Counties, with an area of approximately $11555 \mathrm{~km}^{2}$ and approximately $25.71 \%$ of the study area. The undeveloped areas of geological disasters are mainly distributed in the plain 
area, with an area of approximately $29266 \mathrm{~km}^{2}$ and approximately $65.12 \%$ of the study area.

\section{References}

[1] Zheng, M., S. Niu and H. Zheng, A GIS-based Research on Triggering Factors of Erosive Landslide and Collapse in Yanhe River Basin. 2016. 36 (2): p. 156-160.

[2] Meng, X., et al., GIS-Based susceptibility assessment of geological hazards along the road from Dujiangyan to Wenchuan by factor analysis. 2016. 27 (3): p. 106-115.

[3] Shi, C., X. Lu and Z. Liu, GIS-based zoning of geological hazards susceptibility in Huizhou district of Huangshan city of Anhui province. 2016. 27 (1): p. 136-140.

[4] Niu, Q., et al., Susceptibility Assessment of Disaster Environment for Landslide Hazard based on GIS in Lanzhou Area. 2017. 32 (3): p. 29-35.

[5] Zheng, M., S. Niu and H. Zheng, A GIS-based Research on Triggering Factors of Erosive Landslide and Collapse in Yanhe River Basin. 2016. 36 (2): p. 156-160.
[6] Zhao, B., et al., GIS analysis on seismic geological disasters susceptibility of Wenchuan. 2013. 38 (6): p. 70-72.

[7] Meng, X., et al., GIS-Based susceptibility assessment of geological hazards along the road from Dujiangyan to Wenchuan by factor analysis. 2016. 27 (3): p. 106-115.

[8] Wang, N., et al., Quantitative evaluation of geological disaster liability based on RS \& GIS analysis: A case study of Wufeng County, Hubei Province. 2012. 19 (6): p. 221-229.

[9] Liu, Y., H. Deng and Q. Xiong, AHP-based Evaluation of Slope Geo-hazard Susceptibility of Maoxian County, Sichuan, China. 2017. 34 (5): p. 31-35.

[10] Kaizhen, R. E. N., M. A. O. Jian and C. Guohu, A Discussion on the weights of the influence factors of geological hazards. 2011. 22 (1): p. 80-86.

[11] Liu, Y., H. Deng and Q. Xiong, AHP-based Evaluation of Slope Geo-hazard Susceptibility of Maoxian County, Sichuan, China. 2017. 34 (5): p. 31-35.

[12] Zhou, J., et al., Susceptibility zoning of different types of mountain torrent disasters in the Yangtze River Basin of sourthern China. 2017. 39 (11): p. 56-64. 